\title{
Ginger extract versus Loratadine in the treatment of allergic rhinitis: a randomized controlled trial
}

\author{
Rodsarin Yamprasert', Waipoj Chanvimalueng ${ }^{2}$, Nichamon Mukkasombut ${ }^{1}$ and Arunporn Itharat $^{1,3^{*}}$ (D)
}

\begin{abstract}
Background: Allergic rhinitis (AR) is a non-infectious immune disease and incidents of the disease has continuously increased in Thailand. Ginger, a Thai herb, is used in food and Thai traditional medicine. This study was designed to assess efficacy and safety of ginger extract in comparison with loratadine for AR treatment.

Methods: AR patients were treated with ginger extract $500 \mathrm{mg}(n=40)$ against those treated with loratadine $10 \mathrm{mg}$ $(n=40)$ in a randomized, double-blind, controlled trial for 3 and 6 weeks. The efficacy was evaluated from clinical examinations i.e. total nasal symptom scores (TNSS), cross-sectional area of the nasal cavity with acoustic rhinometry (ARM) and rhinoconjunctivitis quality of life questionnaire (RQLQ). The safety of treatment was measured by blood pressure, blood analysis and history-taking for side effects.

Results: The results showed both ginger extract and loratadine treated groups significantly decreased TNSS scores but there was no significant difference between the two groups. In acoustic rhinometry measurement, the ginger treated group significantly gradually increased the estimated volume of the nasal cavity and decreased distances from the nostril, but the loratadine treated group did not cause a change. Both groups gave significantly improvement in every aspect of the RQLQ at third weeks. The treatment with ginger extract was as safe as loratadine as shown by renal and liver function results obtained from blood analysis. Both treatments had no effect on blood pressure of the patients.
\end{abstract}

Conclusions: The ginger extract is as good as loratadine in improving nasal symptoms and quality of life in AR patients. However, ginger extract caused less side effects especially, drowsiness, fatigue, dizziness and constipation. Therefore, the ginger extract could be used as alternative treatment for patients with AR.

Trial registration: Registered with ClinicalTrials.gov (Registration number: NCT02576808) on 15 October 2015.

Keywords: Ginger extract, Loratadine, Allergic rhinitis, Quality of life, Clinical trials

\footnotetext{
* Correspondence: iarunporn@yahoo.com

'Department of Applied Thai Traditional Medicine, Faculty of Medicine,

Thammasat University, Klongluang, Pathumthani 12120, Thailand

${ }^{3}$ Center of Excellence on Applied Thai Traditional Medicine Research

(CEATMR), Faculty of Medicine, Thammasat University, Klongluang,

Pathumthani 12120, Thailand

Full list of author information is available at the end of the article
}

(C) The Author(s). 2020 Open Access This article is licensed under a Creative Commons Attribution 4.0 International License, which permits use, sharing, adaptation, distribution and reproduction in any medium or format, as long as you give appropriate credit to the original author(s) and the source, provide a link to the Creative Commons licence, and indicate if changes were made. The images or other third party material in this article are included in the article's Creative Commons licence, unless indicated otherwise in a credit line to the material. If material is not included in the article's Creative Commons licence and your intended use is not permitted by statutory regulation or exceeds the permitted use, you will need to obtain permission directly from the copyright holder. To view a copy of this licence, visit http://creativecommons.org/licenses/by/4.0/ The Creative Commons Public Domain Dedication waiver (http://creativecommons.org/publicdomain/zero/1.0/) applies to the data made available in this article, unless otherwise stated in a credit line to the data. 


\section{Background}

AR poses a significant global health problem. It is the most common form of non-infectious rhinitis, affecting 10 to $30 \%$ of all adults and up to $40 \%$ of children. From Epidemiological studies, the worldwide incidents of AR continue to increase. The World Health Organization has estimated that 400 million people in the world are suffering from AR [1]. AR results from specific IgE-mediated allergic reactions in the nasal mucosa and is characterized by a nasal congestion, nasal itching, watery nasal discharge or runny nose, and sneezing [2]. Management of allergic rhinitis has usually focused on suppressing these inflammatory reactions and the main medications are antihistamines, nasal steroids, and leukotriene receptor antagonists [3]. Nowadays, the second-generation non-sedating antihistamines are considered first-line treatment and particularly useful in the treatment of AR. However, anti-histamine has side effects, for example drowsiness, dry mouth, rash or fatigue, etc. [4]. For these reasons it is essential to search for a better-tolerated alternative, especially from herbs.

Ginger (Zingiber officinale Roscoe) is widely used as a spice throughout the world. In Thai traditional medicine, it has been used as a part of herbal remedies for treating cold, constipation, sleeplessness and relieving flatulence, etc. [5]. In other traditions such as Indian and Chinese medicine, ginger has been used for several disorders such as asthma, nausea and arthritis [6]. There is evidence to indicate that the ethanolic extract of ginger exhibited the highest anti-allergic activity by inhibited $\beta$-hexosaminidase release in rat basophilic leukemia (RBL-2H3) cells. Moreover, 6-shogaol and 6-gingerol is major biomarker of antiallergic activity [7]. In an in vivo study, oral administration of $2 \%$ ginger diet decreased the severity of nasal rubbing and sneezing by nasal sensitization of ovalbumin (OVA) and suppressed infiltration of mast cells in nasal mucosa and release of OVA-specific IgE in serum. Furthermore, 6gingerol $(50 \mu \mathrm{M})$ could inhibited cytokine production for $\mathrm{T}$ cell activation and proliferation, therefore $\mathrm{B}$ cell and mast cell could not be activated [8]. In acute and subacute toxicity studies, single oral doses of crude ethanolic extract of ginger at 1000, 3000, and $5000 \mathrm{mg} / \mathrm{kg}$ body weight did not cause mortality in any animal during the investigation period [9]. In addition to this, ginger extracts have been reported to have a wide range of pharmacological properties and many clinical trials have examined the clinical effectiveness of ginger for conditions such as motion sickness [10, 11], nausea and vomiting [12], osteoarthritis [13-15], and diabetes mellitus [16]. However, there has been no clinical report of ginger extract relieving symptoms in patients with AR.

In this study, we conducted a randomized control trial of ginger extract and loratadine; a commonly-used nonsedating antihistamine to compare the efficacy and safety of these treatments.

\section{Methods}

\section{Ginger collection and preparation}

The fresh rhizomes of ginger were collected in May, 2015 from Ratchaburi province, Thailand. The voucher specimen (BKF 192198) was deposited by Office of the Forest Herbarium, Department of National Parks, Wildlife and Plant Conservation, Bangkok, Thailand and was identified by Mr. Sukid Rueangruea, Forestry Technical Operations Investigators Plant Species official, Bangkok Forest Herbarium, Herbarium Department of National Parks, Wildlife and Plant Conservation, Thailand. The ginger rhizomes were cleaned, steamed by autoclave and dried with hot air oven at $50{ }^{\circ} \mathrm{C}$. The quality standards of ginger rhizomes were applied with the following parameters: contamination testing, loss on drying (moisture content), total ash, acid insoluble ash for inorganic contamination, extractive value and heavy metal content [17]. The dried rhizomes were mechanically powdered and extracted by maceration with $95 \%$ ethanol (Liquid: Solid ratio: 1:1) for 3 days and filtered. These were repeated twice, the combined filtrates were concentrated under reduced pressure by a rotary evaporator (Rotavapor R-205, Buchi, Switzerland). Biological quality control of ginger extract was conducted by an anti-allergic assay using the inhibitory effect on $\beta$-hexosaminidase in which $\mathrm{IC}_{50}$ not more than $30 \mu \mathrm{g} / \mathrm{ml}$. The high-performance chromatography (HPLC) was also performed to ensure the composition of 6-gingerol and 6-shogaol. HPLC analysis of the study was carried out according to the method of Pattanacharoenchai [18]. Chromatogram of ginger extract and standard compound are shown in Fig.1. From HPLC analysis, the mean contents of 6gingerol and 6-shogaol in ginger extract were 71.13 and $19.65 \mathrm{mg} / \mathrm{g}$ of extract, respectively.

\section{Drug preparation}

The ginger extract was weighed and combined with necessary excipients, and then filled into $500 \mathrm{mg}$ capsules (redblack capsules for the morning meal and white-blue capsules for the evening meal) each containing $125 \mathrm{mg}$ of the ginger extract, produced according to Good Manufacturing Practice (GMP) for Traditional Medicine. Ginger extract capsules were packed in aluminium foil complied with the quality standards of Thai Herbal Pharmacopeia, contamination testing, weight variation and dissolution. Loratadine (Clarityne ${ }^{\oplus}$ ) tablets containing $10 \mathrm{mg}$ of micronized loratadine were encapsulated in the same size and color as ginger extract. Lactose monohydrate as a placebo was prepared in a $500 \mathrm{mg}$ capsule.

\section{Study design}

This study was a prospective randomized, double blind, controlled trial (Phase 2), designed to investigate the efficacy and safety of ginger extract compared with loratadine 


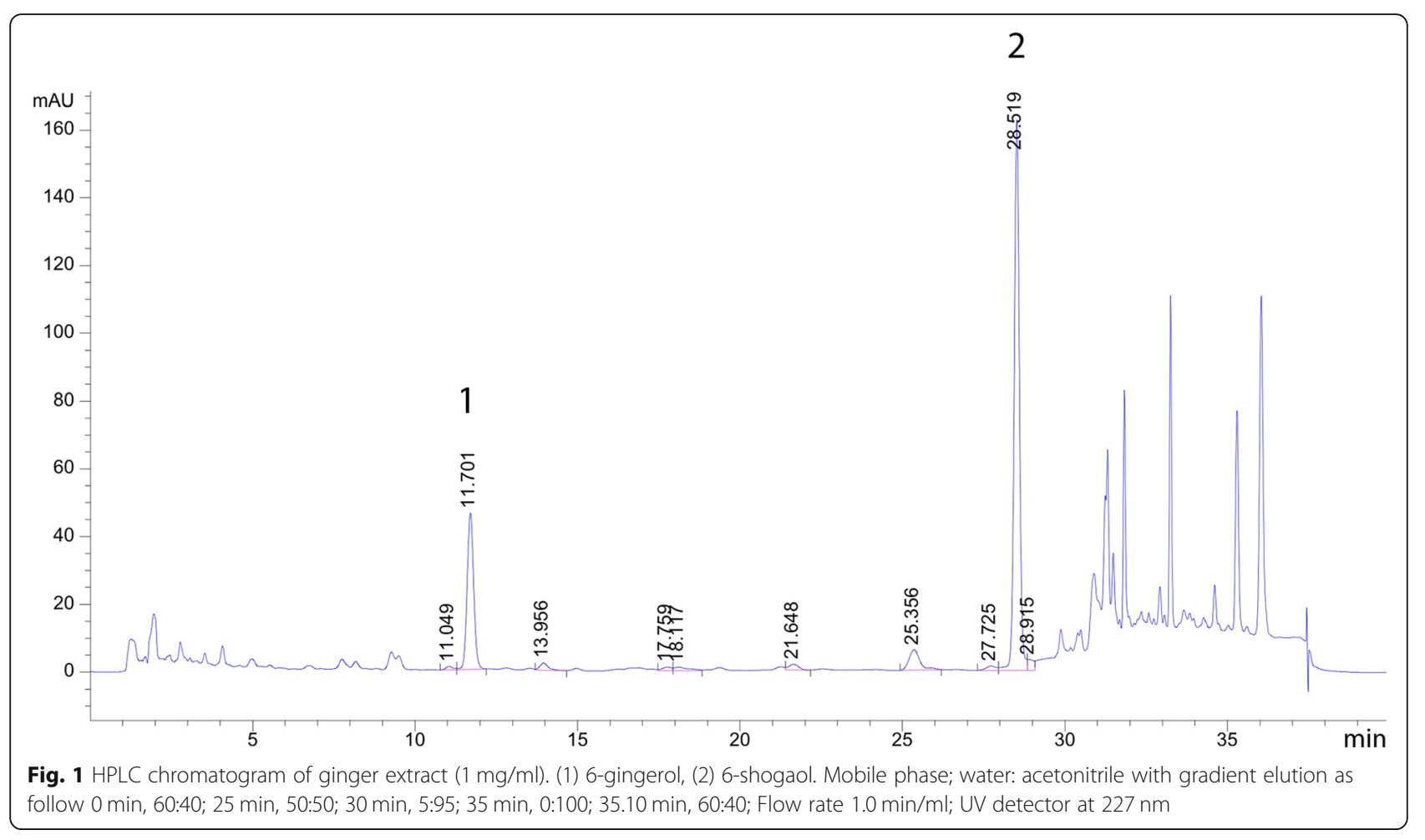

for treating AR patients at Thammasat University Hospital, Pathumthani, Thailand. Before the commencement of the study, the study protocol and informed consent were approved by the Medical Ethics Committee of the Faculty of Medicine, Thammasat University (registry number MTU-EC-TM-4-077/57) and also was registered at ClinicalTrials.gov (NCT02576808).

\section{Study population and protocol}

The sample size determination was calculated from this formula, $N$ (each group) $=(\mathrm{r}+1)\left(\mathrm{Z}_{\alpha / 2}+\mathrm{Z}_{1-\beta}\right)^{2} \sigma^{2} / \mathrm{rd}^{2}$ [19] where $Z \alpha$ is the normal deviate at a level of significance ( $Z \alpha$ is 1.96 for $5 \%$ ) and $Z_{1-\beta}$ is the normal deviate at $1-\beta \%$ power with $\beta \%$ of type II error $(0.84$ at $80 \%$ power. $r=\mathrm{n} 1 / \mathrm{n} 2$ is the ratio of sample size required for 2 groups, generally it is one for keeping equal sample size for 2 groups. $\sigma$ and $d$ are the pooled standard deviation and difference of means of 2 groups.

From conducting a pilot study, the minimal detectable difference means (d) of two group as 0.66 scores of total nasal symptom scale (TNSS) and 1.01 is standard deviation $(\sigma)$.

Thus, the minimum sample size for each group to detect the mean difference between the two means is 36 persons/group. Lastly, considering $10 \%$ of drop-out was count out, so forty patients per each treatment group were required for the study.

Eighty patients from the Department of Ear Nose and Throat, Thammasat University Hospital were between 18 and 70 years old were chosen. The patients had a clinical history of AR symptoms (itching, nasal congestion, watery nasal discharge or runny nose and sneezing) and were diagnosed by doctor with a moderate AR; minimum TNSS scores of 7 points. Patients could stop taking antihistamine or intranasal steroids for 1 week before trial and did not have history of the following disease: heart disease, kidney disease, liver disease, epilepsy, high blood pressure and severe asthma. Exclusion criteria included patients having fever, taking anti-coagulant, anti-platelet aggregation, erythromycin, clarithromycin, ketoconazole, itraconazole and fluconazole, experienced serious side effects from loratadine and ginger allergy. Pregnant and lactating women were also excluded.

Informed consent was obtained from the patients who were eligible for the study. The patients were randomly divided into 2 groups (1:1) by using a computer-generated program ensuring no contact with investigators. The patient received a randomized code number sequentially from a secret random list. Treatment assignment was also concealed from all investigators involving in the trial. The masking was opened in medical emergency or if trial successfully accomplished, opened after data analysis.

All patients were instructed about the same appearance of treatment and to take two capsules two times daily for 6 weeks; the experimental group received ginger extract capsules, or the control group, received loratadine. In this study, all patients were followed up at 3rd 
week and 6th week for evaluating the efficacy, safety, and patient compliance.

\section{The clinical efficacy evaluation}

The efficacy was evaluated by total nasal symptom scores (TNSS) and secondary efficacy variables were measuring the cross-sectional area of the nasal cavity with acoustic rhinometry (ARM) and rhino conjunctivitis quality of life questionnaire (RQLQ).

TNSS score(s), a subjective evaluation as a primary effective tool to measure the intensity symptoms of patients with AR [20], Overall assessment of nose symptoms uses four aspects: runny nose, itchy nose, nasal congestion and sneezing with the score of $4(0=$ no symptoms $-3=$ severe symptoms). The total possible score ranged from 0 (no symptoms) to12 (maximum symptom intensity) [3].
ARM is one of the standard diagnostic tools in objective evaluation of nasal patency. ARM can detect minimal cross section area (MCA); narrow points within the nose that may lead to nasal blockage, volume estimates of the nasal cavity (Vol.) and distance from the nostril (Dis.). The reliability of the method is greatest in the anterior nasal cavity, which is the site of the nasal valve [21].

The RQLQ has 28 questions in 7 domains (activity limitation, sleep problems, nose symptoms, eye symptoms, non-nose/eye symptoms, practical problems and emotional function). There are 3 patient-specific questions in the activity domain which furnish patients to choose 3 activities in which they are mostly limited by their rhino conjunctivitis. Patients gave responses to each question on a 7 -point scale $(0=$ not impaired at all $-6=$ severely impaired). The overall

Table 1 Baseline characteristics of patients

\begin{tabular}{|c|c|c|c|}
\hline Data & Ginger extract $(n=40)$ & Loratadine $(n=40)$ & $p$-value* \\
\hline Female, number (\%) & $28(70)$ & $30(75)$ & $0.617^{c}$ \\
\hline Age; yrs., mean (SD) & $35.42(12.73)$ & $30.75(9.72)$ & $0.069^{\mathrm{a}}$ \\
\hline $\mathrm{BMl} ; \mathrm{Kg} / \mathrm{m}^{2}$, mean (SD) & $21.92(3.34)$ & $21.87(2.99)$ & $0.946^{b}$ \\
\hline Exercise history, number (\%) & $18(45)$ & $25(62.5)$ & $0.116^{c}$ \\
\hline Total TNSS score, mean (SD) & $7.48(1.96)$ & $7.37(2.32)$ & $0.835^{t}$ \\
\hline \multicolumn{4}{|l|}{ MCA $\left(\mathrm{cm}^{2}\right)$, mean $(S D)$} \\
\hline Right MCA & $0.32(0.14)$ & $0.31(0.14)$ & $0.661^{a}$ \\
\hline Left MCA & $0.34(0.16)$ & $0.31(0.18)$ & $0.378^{\mathrm{a}}$ \\
\hline \multicolumn{4}{|l|}{ Volumes $\left(\mathrm{cm}^{3}\right)$ of nasal cavity } \\
\hline Right Vol & $3.83(0.98)$ & $3.62(1.04)$ & $0.365^{a}$ \\
\hline Left Vol & $3.95(1.11)$ & $3.53(1.16)$ & $0.103^{\mathrm{a}}$ \\
\hline \multicolumn{4}{|l|}{ Distance $(\mathrm{cm})$} \\
\hline Right Dis & $2.11(0.31)$ & $2.22(0.25)$ & $0.091^{\mathrm{a}}$ \\
\hline Left Dis & $2.11(0.28)$ & $2.27(0.43)$ & $0.068^{\mathrm{a}}$ \\
\hline Total RQLQ score, mean (SD) & $2.98(0.99)$ & $3.12(1.12)$ & $0.546^{\mathrm{a}}$ \\
\hline \multicolumn{4}{|l|}{ Laboratory data, mean (SD) } \\
\hline \multicolumn{4}{|l|}{ Blood pressure } \\
\hline Systolic (mm. Hg.) & $117.05(9.60)$ & $115.28(13.16)$ & $0.631^{b}$ \\
\hline Diastolic (mm. Hg.) & $75.95(9.49)$ & $72.10(10.15)$ & $0.059^{b}$ \\
\hline \multicolumn{4}{|l|}{ Renal function tests } \\
\hline $\mathrm{BUN}(\mathrm{mg} / \mathrm{dL})$ & $11.81(3.47)$ & $11.50(3.59)$ & $0.698^{\mathrm{a}}$ \\
\hline Creatinine $(\mathrm{mg} / \mathrm{dL})$ & $0.74(0.18)$ & $0.74(0.18)$ & $0.956^{\mathrm{a}}$ \\
\hline \multicolumn{4}{|l|}{ Liver function tests } \\
\hline AST (U/L) & $21.13(6.71)$ & $20.85(8.73)$ & $0.875^{\mathrm{a}}$ \\
\hline ALT (U/L) & $28.38(11.96)$ & $27.05(13.35)$ & $0.641^{a}$ \\
\hline ALP $(U / L)$ & $60.93(13.68)$ & $65.88(21.93)$ & $0.229^{a}$ \\
\hline Eosinophil & $3.65(2.52)$ & $3.92(2.45)$ & $0.829^{b}$ \\
\hline Basophil & $0.51(0.43)$ & $0.40(0.38)$ & $0.308^{b}$ \\
\hline
\end{tabular}

*statistical analysis: ${ }^{a}$ independent two-sample Student's t-test, ${ }^{\mathrm{b}}$ Mann Whitney U Test and 'chi-square test 
RQLQ score is the mean of all 28 responses and the individual domain scores are the means of the items in those domains [22].

\section{The safety evaluation}

The safety is measured by using blood analysis, measuring blood pressure and questionnaire. All patients had blood analysis is preformed, three times (before treatment, 3rd week and 6th week). A $10 \mathrm{cc}$. of blood was taken from each patient in the morning at 7:00 to 9:00 am after $8 \mathrm{~h}$ of fasting. The blood specimen were analysed by The Bangkok Pathology-Laboratory including; liver function test and renal function test. All patients were requested to immediately contact the investigator if they noticed any kind of adverse reactions.

\section{Statistical analysis}

All statistical analyses were performed using the standard statistical software. The independent $t$-test or MannWithney $U$ test was used to compare these mean values between the 2 groups. The repeated measured analysis of

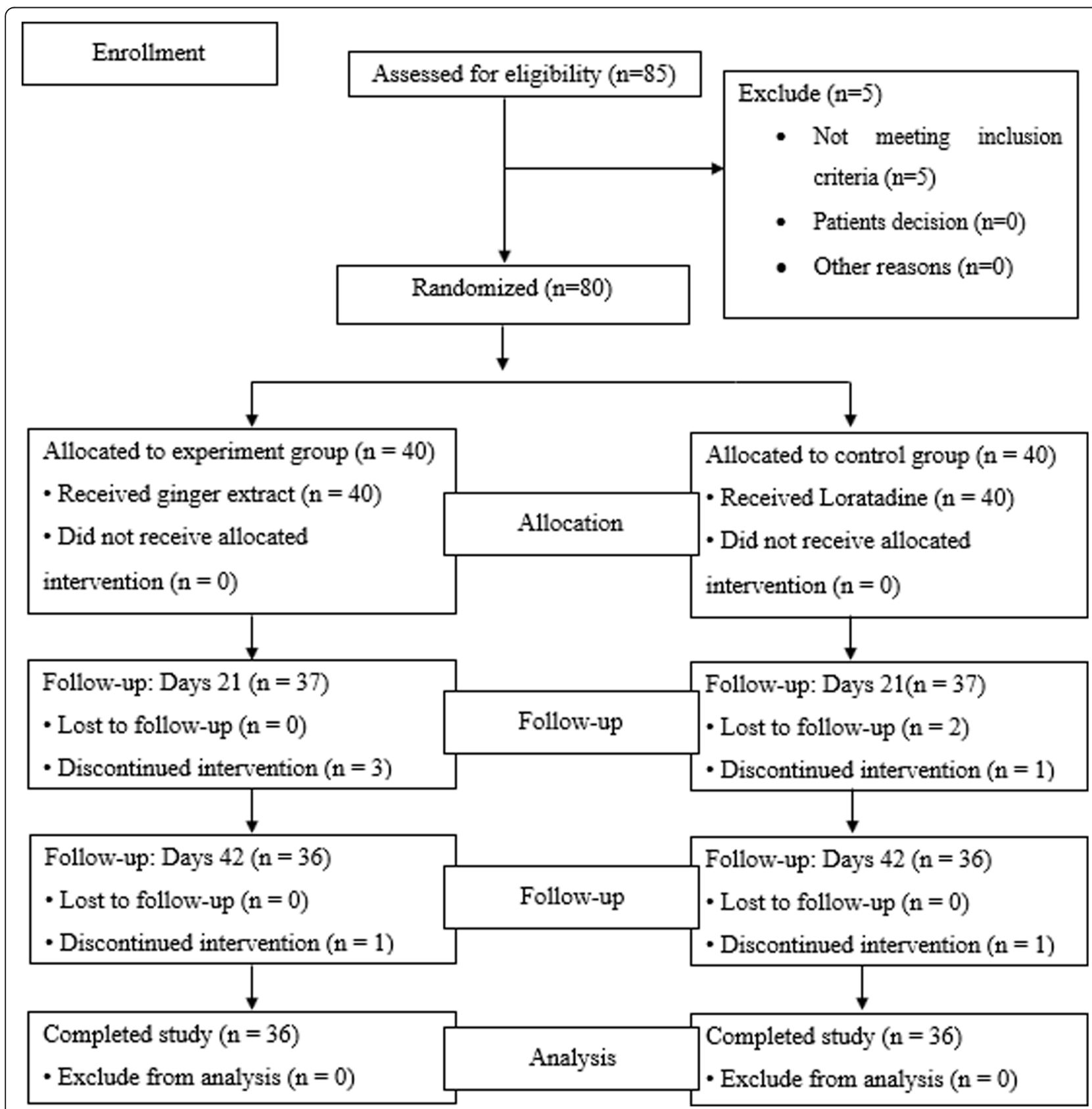

Fig. 2 Enrolment and randomization of study subjects 
Table 2 The score of total nasal symptoms scores of ginger extract and loratadine

\begin{tabular}{|c|c|c|c|c|}
\hline \multirow[t]{2}{*}{ Data $^{a}$} & \multirow{2}{*}{$\begin{array}{l}\text { Follow- } \\
\text { up }\end{array}$} & \multicolumn{2}{|c|}{ Treatment $^{\mathrm{b}}$} & \multirow{2}{*}{$\begin{array}{l}p- \\
\text { value }\end{array}$} \\
\hline & & Ginger extract & Loratadine & \\
\hline \multirow[t]{3}{*}{ Total TNSS score } & Week 0 & 7.48 (1.96) & $7.38(2.32)$ & 0.835 \\
\hline & Week 3 & 4.30 (2.47) †十+ & 4.33 (2.57) †十+ & 0.989 \\
\hline & Week 6 & 3.42 (2.80) t+† & $4.11(2.56) \mathrm{t+十}$ & 0.276 \\
\hline \multirow[t]{3}{*}{ runny nose } & Week 0 & $2.00(0.82)$ & $2.00(1.04)$ & 1.000 \\
\hline & Week 3 & 1.19 (0.82) t†† & $1.28(0.91)+\dagger$ & 0.812 \\
\hline & Week 6 & 0.89 (0.78) +十+ & $1.14(0.96) \mathrm{t+十}$ & 0.231 \\
\hline \multirow[t]{3}{*}{ itchy nose } & Week 0 & $1.65(0.86)$ & $1.60(0.87)$ & 0.797 \\
\hline & Week 3 & 0.89 (0.88) †+十 & $0.81(0.79)$ †十+ & 0.796 \\
\hline & Week 6 & 0.81 (0.88) t†十 & $0.86(0.87)$ t十† & 0.789 \\
\hline \multirow[t]{3}{*}{ nasal congestion } & Week 0 & $2.32(0.62)$ & $2.15(0.77)$ & 0.265 \\
\hline & Week 3 & 1.19 (0.81) ††† & 1.31 (0.95) ††† & 0.718 \\
\hline & Week 6 & $1.00(0.16)$ t十+ & $1.28(0.88)+\dagger$ & 0.204 \\
\hline \multirow[t]{3}{*}{ sneezing } & Week 0 & $1.50(0.99)$ & $1.62(0.93)$ & 0.561 \\
\hline & Week 3 & $1.03(0.93)$ & 0.94 (0.71) †+† & 0.681 \\
\hline & Week 6 & $0.72(0.81) \dagger$ & $0.83(0.77)+\dagger+$ & 0.555 \\
\hline
\end{tabular}

${ }^{a}$ Data represent mean (SD), ${ }^{b}$ Statistical analysis: repeated measured ANOVA, tSignificant difference from day 0 within group $(p<0.05)$, t†significant difference from day 0 within group $(p<0.01)$, andtttsignificant difference from day 0 within group $(p<0.001)$

*** Statistical analysis: Independent two-sample Student's t-test variance (ANOVA) or Friedman's test was used to analyze the changes in the mean values from baseline to 3rd week and 6th week for each group. TNSS score, Total score of RQLQ and ARM values were examined by multivariate regression analyses. Independent variables including treatment with confounders selected demographic and clinical variables (age, gender, body mass index and using steroids). A $p$-value of $<0.05$ was considered to indicate statistical significance.

\section{Results}

\section{Patient characteristics}

Eighty-five patients were initially screened between October 2016-January 2017 and 5 patients were excluded from the study due to abnormal liver function tests. Thus, 80 patients were randomized into 2 groups (40 patients in each group). There was no significant difference between the two groups in age, gender, underlying diseases of AR and laboratory data (Table 1). After the end of study, 72 patients (90\%) completed the study (36 patients in the ginger extract treated group and 36 patients in the loratadine treated group). Eight patients were withdrawn during the study due to failing the follow-up (six patients dropped out at the first follow up and two patients dropped out at the second follow up). The reasons for withdrawn as follow: in ginger extract treated

Table 3 The acoustic rhinometry parameter of ginger extract and loratadine

\begin{tabular}{|c|c|c|c|c|}
\hline \multirow[t]{2}{*}{ Data $^{a}$} & \multirow{2}{*}{$\begin{array}{l}\text { Follow- } \\
\text { up }\end{array}$} & \multicolumn{2}{|c|}{ Treatment $^{\mathrm{b}}$} & \multirow{2}{*}{$\begin{array}{l}p- \\
\text { value*** }\end{array}$} \\
\hline & & Ginger extract & Loratadine & \\
\hline \multirow[t]{3}{*}{ Minimal cross section area of right nose $\left(\mathrm{cm}^{2}\right)$} & Week 0 & $0.32(0.14)$ & $0.31(0.14)$ & 0.661 \\
\hline & Week 3 & $0.34(0.15)$ & $0.32(0.14)$ & 0.771 \\
\hline & Week 6 & $0.37(0.15)$ & $0.32(0.14)$ & 0.120 \\
\hline \multirow[t]{3}{*}{ Minimal cross section area of left nose $\left(\mathrm{cm}^{2}\right)$} & Week 0 & $0.34(0.16)$ & $0.31(0.18)$ & 0.378 \\
\hline & Week 3 & $0.36(0.14)$ & $0.31(0.13)$ & 0.164 \\
\hline & Week 6 & $0.35(0.10)$ & $0.31(0.13)$ & 0.160 \\
\hline \multirow[t]{3}{*}{ Volume estimates of the right nasal cavity $\left(\mathrm{cm}^{3}\right)$} & Week 0 & $3.83(0.98)$ & $3.62(1.04)$ & 0.365 \\
\hline & Week 3 & $3.95(1.18)$ & $3.84(1.21)$ & 0.685 \\
\hline & Week 6 & $4.38(1.42) \dagger$ & $3.63(1.20)$ & $0.018^{*}$ \\
\hline \multirow[t]{3}{*}{ Volume estimates of the left nasal cavity $\left(\mathrm{cm}^{3}\right)$} & Week 0 & $3.95(1.11)$ & $3.53(1.16)$ & 0.103 \\
\hline & Week 3 & $4.28(1.28)$ & $3.65(0.87)$ & $0.014^{*}$ \\
\hline & Week 6 & $4.25(0.99)+$ & $3.67(1.15)$ & $0.027^{*}$ \\
\hline \multirow[t]{3}{*}{ Distance from the nostril of right nose $(\mathrm{cm})$} & Week 0 & $2.11(0.31)$ & $2.22(0.25)$ & 0.091 \\
\hline & Week 3 & $2.15(0.30)$ & $2.16(0.30)$ & 0.828 \\
\hline & Week 6 & $2.19(0.21)$ & $2.16(0.32)$ & 0.607 \\
\hline \multirow[t]{3}{*}{ Distance from the nostril of left nose $(\mathrm{cm})$} & Week 0 & $2.11(0.28)$ & $2.27(0.43)$ & 0.068 \\
\hline & Week 3 & $2.11(0.29)$ & $2.20(0.32)$ & 0.245 \\
\hline & Week 6 & $2.07(0.35)$ & $2.26(0.29)$ & $0.011^{*}$ \\
\hline
\end{tabular}

${ }^{\mathrm{a}}$ Data represent mean (SD), ${ }^{\mathrm{b}}$ Statistical analysis: repeated measured ANOVA, †Significant difference from day 0 within group $(p<0.05)$, ††significant difference from day 0 within group $(p<0.01)$, and $+\dagger+$ significant difference from day 0 within group $(p<0.001)$

*** Statistical analysis: Independent two-sample Student's t-test 
group, two patients used other anti-histamine, one patient had food poisoning and one patient experienced nausea and dizziness. In loratadine treated group, one patient was unsatisfied with the efficacy of loratadine, one patient had Hepatitis A and two patients left the trial (Fig. 2).

\section{The clinical efficacy evaluation}

The results showed that the ginger extract and the loratadine treated groups significantly decreased the TNSS scores with no statistically significant difference between the two treated groups. The four main symptoms were separately assessed i.e. itching, runny nose, nasal congestion and sneezing the first 3 symptoms decreases in the third week. The sneezing symptom, in the ginger treated groups showed significant reduction in week 6 but loratadine treatment could reduce sneezing in 3 weeks (Table 2).
In ARM performed, the ginger extract treated group gradually increased in minimal cross section area at week 3 but not statistically significant. The volume estimates of nasal cavity were significantly improved at week 6. On the other hand, loratadine treated group did not show improvement. When comparing the differences between the two treated groups, the result showed that there was significant difference in the volume at week 6 (Table 3).

After treatment for 3 weeks, the quality of life of both treated groups significantly improved in every aspect scores. (Table 4).

After adjusting for possible differences in clinical characteristics between the treatment groups, the results showed that the TNSS scores of the ginger extract treated group consistently decreased at week 3 and 6 and were better than loratadine group, $(0.666$ and 0.574 scores, respectively). As for ARM value, the ginger extract treated group significantly increased the volume of

Table 4 The score of quality of life of ginger extract and loratadine

\begin{tabular}{|c|c|c|c|c|}
\hline \multirow[t]{2}{*}{$\overline{\text { Data }^{a}}$} & \multirow{2}{*}{$\begin{array}{l}\text { Follow- } \\
\text { up }\end{array}$} & \multicolumn{2}{|c|}{ Treatment } & \multirow{2}{*}{$\begin{array}{l}p- \\
\text { value }^{* *}\end{array}$} \\
\hline & & Ginger extract & Loratadine & \\
\hline \multirow[t]{3}{*}{ Total RQLQ score } & Week 0 & $2.98(0.99)$ & $3.12(1.12)$ & 0.547 \\
\hline & Week 3 & 1.88 (0.96) ††† & $1.92(1.17)$ ††† & 0.881 \\
\hline & Week 6 & $1.34(0.95)+\dagger+$ & 1.44 (1.06) ††† & 0.660 \\
\hline \multirow[t]{3}{*}{ Activity limitation } & Week 0 & $3.95(1.08)$ & $4.32(0.99)$ & 0.119 \\
\hline & Week 3 & 2.64 (1.31) t†† & 2.98 (1.41) ††† & 0.279 \\
\hline & Week 6 & 1.75 (1.27) ††† & 2.15 (1.36) ††† & 0.211 \\
\hline \multirow[t]{3}{*}{ Sleep problems } & Week 0 & $3.00(1.46)$ & $2.93(1.58)$ & 0.827 \\
\hline & Week 3 & 1.87 (1.32) ††† & 1.50 (1.22) ††† & 0.209 \\
\hline & Week 6 & $1.13(1.23)++†$ & $1.18(1.24)+\dagger+$ & 0.861 \\
\hline \multirow[t]{3}{*}{ Non-nose/eye symptoms } & Week 0 & $2.82(1.28)$ & $2.96(1.44)$ & 0.653 \\
\hline & Week 3 & 1.65 (1.01) +†† & $1.92(1.40)+\dagger$ & 0.339 \\
\hline & Week 6 & 1.30 (1.13) ††十 & 1.37 (1.19) ††† & 0.819 \\
\hline \multirow[t]{3}{*}{ Practical problems } & Week 0 & $3.07(1.52)$ & $3.50(1.55)$ & 0.210 \\
\hline & Week 3 & $2.04(1.34)+\dagger$ & $2.17(1.50)$ †十† & 0.713 \\
\hline & Week 6 & 1.57 (1.35) ††十 & 1.59 (1.22) ††† & 0.946 \\
\hline \multirow[t]{3}{*}{ Nose symptoms } & Week 0 & $3.48(1.20)$ & $3.92(1.38)$ & 0.129 \\
\hline & Week 3 & 2.28 (1.30) t+† & $2.33(1.33)+\dagger$ & 0.864 \\
\hline & Week 6 & 1.67 (1.36) t†† & 1.96 (1.31) ††† & 0.379 \\
\hline \multirow[t]{3}{*}{ Eye symptoms } & Week 0 & $2.39(1.44)$ & $2.28(1.81)$ & 0.772 \\
\hline & Week 3 & 1.47 (1.44) ††† & 1.28 (1.50) ††† & 0.578 \\
\hline & Week 6 & 1.05 (1.16) t†† & 1.00 (1.28) ††† & 0.864 \\
\hline \multirow[t]{3}{*}{ Emotion } & Week 0 & $2.32(1.53)$ & $2.10(1.54)$ & 0.537 \\
\hline & Week 3 & 1.46 (1.22) ††† & 1.31(1.33) †十† & 0.627 \\
\hline & Week 6 & 0.94 (0.95) ††† & 0.96 (1.06) ††† & 0.948 \\
\hline
\end{tabular}

${ }^{a}$ Data represent mean (SD), **Statistical analysis: repeated measured ANOVA, †Significant difference from day 0 within group $(p<0.05)$, ††significant difference from day 0 within group $(p<0.01)$, and $+\dagger+$ significant difference from day 0 within group $(p<0.001)$

*** Statistical analysis: Independent two-sample Student's t-test 
Table 5 Clinical efficacy change score by multivariate regression analyses parameter estimates

\begin{tabular}{|c|c|c|c|c|c|}
\hline \multirow[t]{2}{*}{ Data } & \multirow[t]{2}{*}{ Treatment } & \multirow[t]{2}{*}{ Mean \pm SD } & \multicolumn{2}{|c|}{ 95\% Conf.Interval } & \multirow{2}{*}{$\begin{array}{l}p^{-} \\
\text {value }\end{array}$} \\
\hline & & & lower & upper & \\
\hline \multirow[t]{2}{*}{ TNSS score } & Loratadine & $-0.574(0.709)$ & -0.416 & -0.732 & \multirow[t]{2}{*}{0.343} \\
\hline & Ginger extract & $-0.666(0.649)$ & -0.522 & -0.811 & \\
\hline \multirow[t]{2}{*}{ Minimal cross section area of right nose $\left(\mathrm{cm}^{2}\right)$} & Loratadine & $0.004(0.032)$ & -0.003 & 0.011 & \multirow[t]{2}{*}{0.551} \\
\hline & Ginger extract & $0.007(0.037)$ & -0.001 & 0.016 & \\
\hline \multirow[t]{2}{*}{ Minimal cross section area of left nose $\left(\mathrm{cm}^{2}\right)$} & Loratadine & $-0.001(0.033)$ & -0.008 & 0.006 & \multirow[t]{2}{*}{0.2357} \\
\hline & Ginger extract & $0.005(0.033)$ & -0.002 & 0.012 & \\
\hline \multirow[t]{2}{*}{ Volume estimates of the right nasal cavity $\left(\mathrm{cm}^{3}\right)$} & Loratadine & $0.011(0.285)$ & -0.052 & 0.075 & \multirow[t]{2}{*}{0.106} \\
\hline & Ginger extract & $0.086(0.326)$ & 0.014 & 0.159 & \\
\hline \multirow[t]{2}{*}{ Volume estimates of the left nasal cavity $\left(\mathrm{cm}^{3}\right)$} & Loratadine & $-0.006(0.265)$ & -0.065 & 0.053 & \multirow[t]{2}{*}{$0.02^{*}$} \\
\hline & Ginger extract & $0.094(0.288)$ & 0.030 & 0.158 & \\
\hline \multirow[t]{2}{*}{ Distance from the nostril of right nose $(\mathrm{cm})$} & Loratadine & $-0.003(0.076)$ & -0.020 & 0.014 & \multirow[t]{2}{*}{0.402} \\
\hline & Ginger extract & $0.006(0.066)$ & -0.008 & 0.021 & \\
\hline \multirow[t]{2}{*}{ Distance from the nostril of left nose $(\mathrm{cm})$} & Loratadine & $0.010(0.079)$ & -0.008 & 0.027 & \multirow[t]{2}{*}{$0.008^{*}$} \\
\hline & Ginger extract & $-0.023(0.097)$ & -0.045 & -0.002 & \\
\hline \multirow[t]{2}{*}{ Total RQLQ score } & Loratadine & $-0.266(0.299)$ & -0.199 & -0.332 & \multirow[t]{2}{*}{0.701} \\
\hline & Ginger extract & $-0.283(0.276)$ & -0.222 & -0.345 & \\
\hline
\end{tabular}

Statistical analysis: multivariate regression

left nose with $0.094 \mathrm{~cm}^{3}(p=0.02)$ and decreased distance of left nose with $0.023 \mathrm{~cm}(p<0.01)$. In contrast, loratadine treated group did not show significant improvement. In total score of RQLQ, the ginger extract group showed reduced score with 0.283 points but no significant difference from loratadine group with 0.266 points (Table 5).

\section{The safety evaluation}

The side effects having highest occurrence in ginger extract treated group were eructation $(72.22 \%)$, dry mouth (11.11\%) and throat (11.11\%). In loratadine group, drowsiness was the most common event (25\%) and other side effects, for example dry throat, eructation, dry mouth (19.44, 16.67 and $13.89 \%$, respectively) (Table 6). In both groups, the systolic and diastolic blood pressure

Table 6 Side effects of Ginger extract and Loratadine

\begin{tabular}{lll}
\hline Side effect & \multicolumn{1}{c}{$\begin{array}{c}\text { Ginger extract }(\boldsymbol{n}=36) \\
\text { Number }(\%)\end{array}$} & $\begin{array}{c}\text { Loratadine }(\boldsymbol{n}=36) \\
\text { Number }(\%)\end{array}$ \\
\hline eructation & $26(72.22)$ & $6(16.67)$ \\
drowsiness & $1(2.78)$ & $9(25)$ \\
dry mouth & $4(11.11)$ & $5(13.89)$ \\
dry throat & $4(11.11)$ & $7(19.44)$ \\
keen nose & 0 & $2(5.56)$ \\
fatigue & $1(2.77)$ & $4(11.11)$ \\
dizziness & $1(2.77)$ & $3(8.33)$ \\
constipation & 0 & $3(8.33)$ \\
\hline
\end{tabular}

measurements were not significantly different from baseline and also not significantly different between treated groups (Table 7). All patients were examined for blood urine nitrogen (BUN) and creatinine for renal function tests and aspartate transaminase (AST), alanine aminotransferase (ALT), and alkaline phosphatase (ALP) for liver function tests at third and sixth weeks. The renal function was similar in both groups when compared with their baseline values. For liver function tests, in both treated groups were not significantly different AST and ALT level from baseline. Moreover, the ginger extract treated group slightly decreased ALP levels at week 6 while the loratadine treated group showed an increased ALP level which was significantly difference from ginger extract treated group.

\section{Discussion}

Allergic inflammation process is divided into two phases as follows; sensitization phase which is process of IgE production after exposure to the allergen and clinical phase where many symptoms appear during exposure to allergens. The clinical phase is divided into an early phase response, which involves degranulation of mast cells such as histamine, leukotriene $\mathrm{C} 4$ (LTC4), prostaglandin D2 (PGD2), release cytokines such as interleukin (IL)- 3, IL-4, IL-5, and IL-13 [2] and tumor necrosis factor-alpha (TNF-a) [23]. In latephase response, which is associated with an increase in inflammatory cells in the nasal mucosa and increased secretion of cytokines results in recurrent 
Table 7 Blood pressure, renal functions, and liver functions in safety issue

\begin{tabular}{|c|c|c|c|c|c|}
\hline Data $^{a}$ & Treatment & Week 0 & Week 3 & Week 6 & $p$-value ${ }^{* *}$ \\
\hline \multicolumn{6}{|l|}{ Blood pressure } \\
\hline Systolic blood pressure & Ginger extract & $117.05(9.60)$ & $113.76(9.73)$ & $111.54(17.91)$ & 0.767 \\
\hline (Normal $\leq 140$ mm.Hg.) & Loratadine & $115.28(13.16)$ & $114.37(12.44)$ & $114.25(14.86)$ & \\
\hline Diastolic blood pressure & Ginger extract & $75.95(9.48)$ & $73.73(9.99)$ & $74.58(12.65)$ & 0.112 \\
\hline (Normal $\leq 90$ mm.Hg.) & Loratadine & $72.10(10.15)$ & $70.08(11.74)$ & $71.19(11.88)$ & \\
\hline Renal functions & & & & & 0.729 \\
\hline Blood urea nitrogen; BUN (mg/dL) & Ginger extract & $11.81(3.47)$ & $11.26(2.48)$ & $10.77(3.32)$ & \\
\hline (ref. range $=7.0-18.0$ ) & Loratadine & $11.50(3.59)$ & $11.32(2.71)$ & $10.61(2.26)$ & \\
\hline Creatinine (mg/dL) & Ginger extract & $0.74(0.18)$ & $0.76(0.19)$ & $0.74(0.23)$ & 0.826 \\
\hline (ref. range $=0.7-1.3$ ) & Loratadine & $0.74(0.18)$ & $0.75(0.18)$ & $0.75(0.16)$ & \\
\hline \multicolumn{6}{|l|}{ Liver functions } \\
\hline \multirow[t]{2}{*}{ AST $(\mathrm{U} / \mathrm{L})$ (ref. range $=15-37$ ) } & Ginger extract & $21.13(6.71)$ & $19.81(5.18)$ & $20.19(6.92)$ & 0.871 \\
\hline & Loratadine & $20.85(8.73)$ & $24.38(14.66)$ & $20.56(5.95)$ & \\
\hline \multirow[t]{2}{*}{$\mathrm{ALT}(\mathrm{U} / \mathrm{L})$ (ref. range $=30-65)$} & Ginger extract & $28.38(11.96)$ & $27.51(12.92)$ & $26.78(11.39)$ & 0.586 \\
\hline & Loratadine & $27.05(13.35)$ & $29.51(20.52)$ & $27.08(12.28)$ & \\
\hline \multirow[t]{2}{*}{ ALP $(U / L)$ (ref. range $=46-116)$} & Ginger extract & $60.93(13.68)$ & $62.30(16.73)$ & $58.11(17.66)$ & 0.118 \\
\hline & Loratadine & $65.88(21.93)$ & $67.89(25.00)$ & $68.72(25.04)$ & \\
\hline
\end{tabular}

${ }^{2}$ Data represent mean (SD), ${ }^{*}$ Statistical analysis: repeated measured ANOVA, + Significant difference from day 0 within group $(p<0.05),++$ significant difference from day 0 within group $(p<0.01)$, andt+tsignificant difference from day 0 within group $(p<0.001)$

symptoms. AR is an allergic inflammatory disease of the nasal airway causing chronic symptoms that continuously fluctuate in severity over time, discomfort and a decrease in quality of life. For this reason, early symptomatic treatment through inflammation control is important. Because of the chronic nature of allergic inflammation, some patients are reluctant to take long-term medication and so turn to unverified alternative medications.

Ginger is one of the most widely consumed spices worldwide. It has a long history using as herbal medicine to treat a variety of ailments. Many trials examined the clinical effectiveness of ginger for conditions such as osteoarthritis, nausea and vomiting, and flatulence or indigestion.

Management of AR has usually focused on suppressing these inflammatory reactions [3]. Therefore, ginger has a tendency to target the symptoms of AR by anti-allergic and anti-inflammatory mechanisms. This is confirmed by the researchers who found that the ethanolic extract of ginger inhibited allergic reactions in rat basophilic leukemia (RBL-2H3) cells, with an $\mathrm{IC}_{50}$ value of $12.93 \pm 1.28 \mu \mathrm{g} / \mathrm{ml}$. Moreover, 6-shogaol and 6-gingerol, the major compounds in ginger extract, exhibited the highest anti-allergic activity at $\mathrm{IC}_{50}$ value of $0.28 \pm 0.11 \mathrm{mg} / \mathrm{ml}(1.01 \mu \mathrm{M})$ and $18.30 \pm$ $3.38 \mathrm{mg} / \mathrm{ml}(62.16 \mu \mathrm{M})$, respectively [7]. Kawamoto and team studied the anti-allergic effects of ginger and 6gingerol by using a mouse allergy model. The result presented that $2 \%$ dietary ginger reduced the severity of nasal rubbing and sneezing by nasal sensitization of OVA and suppressed infiltration of mast cells in nasal mucosa and secretion of OVA specific IgE in serum. After spleen cells were induced with OVA, 6-Gingerol $(50 \mu \mathrm{M})$ inhibited the expression Th2 cytokine (IL-4, IL-10 and IL-13) and Th1cytokine (IFN- $\gamma$ ) [8].

There are also studies on anti-inflammatory ability which found that ginger has highest anti-inflammatory activity. Ginger extract showed strong inhibitory effect of the release of IL-1b in human peripheral blood mononuclear cells (PBMCs) [24], COX-1 and COX-2 [25]. In previous study, active ingredients, 6-shogaol and 6-gingerol, presented the most potent to reduce TNF-a release [7].

Dose of drugs were followed from Reference Dose (RfD). A reference dose is the United States Environmental Protection Agency's maximum acceptable oral dose of a toxic substance. RfD is obtained from probabilistic multiplication of NOAEL (No-Observed-AdverseEffect-Level) value which is tested for acute toxicity, sub-chronic toxicity and chronic toxicity in laboratory animals, and has to be safe and with no undesirable effects. The previous study has shown that ethanolic extract of ginger at $5000 \mathrm{mg} / \mathrm{kg}$ did not toxicity in both acute and sub-acute toxicity [9]. Therefore, the calculation maximum dose with no adverse effects of the ginger extract is $3 \mathrm{~g}$ or $3000 \mathrm{mg}$ per day. In another clinical study of 261 osteoarthritis patients, $255 \mathrm{mg}$ of ginger extract twice a day for 6 months, can significantly relieve 
pain better than placebo although patients receiving ginger extract had unpleasant gastrointestinal sensations which were not a serious event [13]. Thus, this study used $500 \mathrm{mg}$ of ginger extract per day per volunteer.

These results urge the conclusion that ginger extract is an excellent anti-allergic and anti-inflammatory agent and it is consistent with this study that taking ginger extract continuously for 6 weeks can relieve the symptoms of allergic rhinitis and improve the quality of life for patients. In addition, there were volunteers who consumed ginger extract to help relieve flatulence and improved defecation at 50 and $23 \%$, respectively.

The TNSS is a widely accepted and reliable tool to assess the efficacy of a drug for treating AR, and the decrease of the score indicate that an overall clinical improvement in the condition. This study showed that AR patients treating with ginger extract could reduce total TNSS and four main symptoms i.e. itching, runny nose, nasal congestion and sneezing.

ARM is used to objectively measure the minimal crosssectional area and volumes of nasal cavities in various depths when measured from the front into the nostril, by analysing reflections of a sound pulse introduced via the nostrils. The technique is a rapid, reproducible, painless, non-invasive procedure that requires little cooperation of the patients and has been applied to both children and adults. This study shows that the ginger extract group had significantly increased volume and decreased distant of left nose, it means improved nasal congestion. Nasal congestion is related with acute allergic inflammation and chronic inflammation of mast cells. The second-generation nonsedating antihistamines, which are generally effective on suppress histamine-mediated symptoms such as sneezing and nasal discharge, are generally not effective in relieving symptoms of nasal congestion; a phenomenon driven by a number of vasoactive mediators in addition to histamine on mast cells [26]. Therefore, anti-histamines are often prescribed in combination with decongestants, which perform to constrict the blood vessels in the mucous membranes and thus diminish nasal congestion. Therefore, ginger extract may be used to treat AR patients either as single drug or in combination with loratadine in case severe sneezing.

AR has been associated with significant impairments in quality of life, sleep and work performance. Assessment of quality of life has now become a standard of allergy clinical trials. Ginger extract reduced RQLQ scores in every aspect which the results represented ginger could improve their quality of life.

The result of blood analysis did not shown any toxicity, therefore we suggest that ginger extract is safe and can be used to treat AR patients.

This is the first research report on treatment of AR patients with ginger extract and its comparison with loratadine. The limitation of this study was short-term and small-scale study. Future studies long-term period and large-scale are needed to completely evaluate the efficacy and safety of ginger extract.

\section{Conclusion}

This study showed that ginger extract could reduce AR symptoms and is safe to use with very mild GI side effect such as eructation. Ginger extract is better than loratadine in causing less drowsiness, fatigue, dizziness and constipation.

\section{Abbreviations}

ALP: Alkaline phosphatase; ALT: Alanine aminotransferase; AR: Allergic rhinitis; ARM: Acoustic rhinometry; AST: Aspartate transaminase; BUN: Blood urea nitrogen; Dis: Distance from the nostril; GMP: Good Manufacturing Practice; HPLC: High-performance chromatography; LL: Interleukin; MCA: Minimal cross section area; PGD2: Prostaglandin D2; RBL-2H3: Rat basophilic leukemia; RQLQ: Rhinoconjunctivitis quality of life questionnaire; TNF-a: Tumor necrosis factor-alpha; TNSS: Total nasal symptom scores; Vol: Volume estimates of the nasal cavity

\section{Acknowledgements}

The author would like to thank Thai Traditional Medical Knowledge, Center of Excellence in Applied Thai Traditional Medicine Research and Faculty of Medicine, Thammasat University for support and providing laboratory facilities and Ear, Nose and Throat Department, Thammasat University Hospital for providing the research facilities location for screen volunteers. The authors gratefully acknowledge Mr. Norman Magnell, for her kind help in grammatical editing and his advice in writing.

\section{Authors' contributions}

RY who is a student in Doctor of Philosophy Program did the whole laboratory and clinical study, WC who is the supervisor of RY and otolaryngology medical doctor contributed to study design on clinical trial and helped in diagnosis, recruitment of patients into this study, and suggestions for writing manuscript, NM who is assistant researcher of Al helped RY to do all this project, and finally Al who is project manager and is also a supervisor of RY contributed to submit research grant and helped RY to evaluate results on all laboratory such as prepare Ginger capsule,

Loratadine and placebo and determined for 6-gingerol and 6-shogaol content, also evaluated clinical study, wrote, proved and is the correspondent of this manuscript. All authors have read and approved the manuscript.

\section{Funding}

The project was supported by Thai Traditional Medical Knowledge Fund, the National Research University Project of Thailand Office of higher Education Commission, Centre of Excellence in Applied Thai Traditional Medicine Research (CEATMR) and Faculty of Medicine, Thammasat University, Thailand. The funders had no role in study design, data collection and analysis, decision to publish, or preparation of the manuscript.

\section{Availability of data and materials}

Dataset of this manuscript has not been deposited in any repository. All dataset and materials are available from the corresponding author upon reasonable request.

\section{Ethics approval and consent to participate}

The study protocol and informed consent were got approved by the Medical Ethics Committee of the Faculty of Medicine, Thammasat University (registry number MTU-EC-TM-4-077/57) and also was registered at ClinicalTrials.gov (NCT02576808). Patients were provided information and voluntarily signed the consent form to participate in the study before any study related activity was undertaken. 


\section{Competing interests}

The authors declare that they have no competing interests.

\section{Author details}

'Department of Applied Thai Traditional Medicine, Faculty of Medicine, Thammasat University, Klongluang, Pathumthani 12120, Thailand.

2Department of Otolaryngology, Faculty of Medicine, Thammasat University, Klongluang, Pathumthani 12120, Thailand. ${ }^{3}$ Center of Excellence on Applied Thai Traditional Medicine Research (CEATMR), Faculty of Medicine,

Thammasat University, Klongluang, Pathumthani 12120, Thailand.

Received: 15 June 2019 Accepted: 28 February 2020

Published online: 20 April 2020

\section{References}

1. Pawankar R, Canonica GW, Holgate ST, Lockey RF, Blaiss MS. WAO white book on allergy: update 2013 executive summary. Milwaukee: World Allergy Organization; 2013.

2. Small P, Kim H. Allergic rhinitis. Allergy Asthma Clin Immunol. 2011;7(Suppl 1):S3.

3. Brożek JL, Bousquet J, Agache I, Agarwal A, Bachert C, Bosnic-Anticevich S, et al. Allergic rhinitis and its impact on asthma (ARIA) guidelines-2016 revision. J Allergy Clin Immunol. 2017;140(4):950-8. https://doi.org/10.1016/j. jaci.2017.03.050 Epub 2017 Jun 8.

4. Akdis CA, Hellings PW, Agache I, editors. Global atlas of allergic rhinitis and chronic rhinosinusitis. Zurich: European Academy of Allergy and Clinical Immunology; 2015.

5. Ministry of Health, Thailand. National List of Essential Medicines. 2013 Thailand. http://drug.fda.moph.go.th:81/nlem.in.th/. Accessed 27 Jan 2018.

6. Grzanna R, Lindmark L, Frondoza CG. Ginger —an herbal medicinal product with broad anti-inflammatory actions. J Med Food. 2005 Summer;8(2):125-32.

7. Makchuchit S, Rattarom R, Itharat A. The anti-allergic and anti-inflammatory effects of Benjakul extract (a Thai traditional medicine), its constituent plants and its some pure constituents using in vitro experiments. Biomed Pharmacother. 2017:89:1018-26.

8. Kawamoto Y, Ueno Y, Nakahashi E, Obayashi M, Sugihara K, Qiao S, et al Prevention of allergic rhinitis by ginger and the molecular basis of immunosuppression by 6-gingerol through T cell inactivation. J Nutr Biochem. 2016;27:112-22.

9. Plengsuriyakarn T, Viyanant V, Eursitthichai V, Tesana S, Chaijaroenkul W, Itharat A, Na-Bangchang K. Cytotoxicity, toxicity, and anticancer activity of Zingiber officinale roscoe against cholangiocarcinoma. Asian Pac J Cancer Prev. 2012;13(9):4597-606.

10. Lien HC, Sun WM, Chen YH, Kim H, Hasler W, Owyang C. Effects of ginger on motion sickness and gastric slow-wave dysrhythmias induced by circular vection. Am J Physiol Gastrointest Liver Physiol. 2003;284(3):G481-9.

11. Holtmann S, Clarke AH, Scherer H, Höhn M. The anti-motion sickness mechanism of ginger: a comparative study with placebo and dimenhydrinate. Acta Otolaryngol. 1989;108(3-4):168-74.

12. Saberi F, Sadat Z, Abedzadeh-Kalahroudi M, Taebi M. Effect of ginger on relieving nausea and vomiting in pregnancy: a randomized, placebocontrolled trial. Nurs Midwifery Stud. 2014;3(1):e11841 Epub 2014 Apr 17.

13. Altman RD, Marcussen KC. Effects of a ginger extract on knee pain in patients with osteoarthritis. Arthritis Rheum. 2001;44(11):2531-8.

14. Zakeri Z, Izadi S, Bari Z, Soltani F, Narouie B, Ghasemi-rad M. Evaluating the effects of ginger extract on knee pain, stiffness and difficulty in patients with knee osteoarthritis. J Med Plant Res. 2011;5(15):3375-9.

15. Naderi Z, Mozaffari-Khosravi H, Dehghan A, Nadjarzadeh A, Huseini HF. Effect of ginger powder supplementation on nitric oxide and C-reactive protein in elderly knee osteoarthritis patients: A 12-week double-blind randomized placebo-controlled clinical trial. J Tradit Complement Med, 101 016/jjtcme201412007 eCollection. 2015;6(3):199-203 2016 Jul.

16. Li Y, Tran VH, Duke CC, Roufogalis BD. Preventive and protective properties of Zingiber officinale (ginger) in diabetes mellitus, diabetic complications, and associated lipid and other metabolic disorders: a brief review. Evid Based Complement Alternat Med. 2012;516870. https://doi.org/10.1155/ 2012/516870 Epub 2012 Nov 22.

17. Department of Medical Sciences. Thai Herbal Pharmacopoeia 2016. Thailand: Department of Medical Sciences, Ministry of Public Health Nonthaburi; 2016.

18. Pattanacharoenchai N. Anti-allergic activity of Trikatuk, Triphala and Trisarn remedy [dissertation]: Faculty of Medicine: Thammasat University; 2016.
http://ethesisarchive.library.tu.ac.th/thesis/2016/TU_2016_5611030015_612 0_4708.pdf.

19. Suresh KP, Chandrashekara S. Sample size estimation and power analysis for clinical research studies. J Hum Reprod Sci. 2012;5(1):7-13.

20. Canonica GW, Baena-Cagnani CE, Bousquet J, Bousquet PJ, Lockey RF, Malling HJ, Passalacqua G, Potter P, Valovirta E. Recommendations for standardization of clinical trials with allergen specific immunotherapy for respiratory allergy. A statement of a world allergy organization (WAO) taskforce. Allergy. 2007;62(3):317-24.

21. Fisher EW, Lund VJ, Scadding GK. Acoustic rhinometry in rhinological practice: discussion paper. J R Soc Med. 1994;87(7):411-3.

22. Juniper EF, Guyatt GH. Development and testing of a new measure of health status for clinical trials in rhinoconjunctivitis. Clin Exp Allergy. 1991; 21(1):77-83

23. Sawaguchi M, Tanaka S, Nakatani $Y$, Harada $Y$, Mukai K, Matsunaga $Y$, Ishiwata K, Oboki K, Kambayashi T, Watanabe N, Karasuyama H. Role of mast cells and basophils in IgE responses and in allergic airway hyperresponsiveness. J Immunol. 2012;188(4):1809-18. https://doi.org/10. 4049/jimmunol.1101746 Epub 2012 Jan 16.

24. Salim E, Kumolosasi E, Jantan I. Inhibitory effect of selected medicinal plants on the release of pro-inflammatory cytokines in lipopolysaccharidestimulated human peripheral blood mononuclear cells. J Nat Med. 2014; 68(3):647-53. https://doi.org/10.1007/s11418-014-0841-0 Epub 2014 May 6.

25. Van Breemen RB, Tao Y, Li W. Cyclooxygenase-2 inhibitors in ginger (Zingiber officinale). Fitoterapia. 2011;82(1):38-43. https://doi.org/10.1016/j. fitote.2010.09.004 Epub 2010 Sep 15.

26. Chiang Y, Shyur S, Chen T, Huang LH, Wen T, Lin M, Yang H, Liang P, Kao Y, Wang TC. A randomized controlled trial of cetirizine plus pseudoephedrine versus loratadine plus pseudoephedrine for perennial allergic rhinitis. Asian Pac J Allergy Immunol. 2006;24(2-3):97-103.

\section{Publisher's Note}

Springer Nature remains neutral with regard to jurisdictional claims in published maps and institutional affiliations.

Ready to submit your research? Choose BMC and benefit from:

- fast, convenient online submission

- thorough peer review by experienced researchers in your field

- rapid publication on acceptance

- support for research data, including large and complex data types

- gold Open Access which fosters wider collaboration and increased citations

- maximum visibility for your research: over $100 \mathrm{M}$ website views per year

At BMC, research is always in progress.

Learn more biomedcentral.com/submissions 